\title{
Resíduos sólidos urbanos como temática para o ensino de ciências na Educação de Jovens e Adultos (EJA)
}

\author{
Municipal solid waste as a theme for science education in the Youth and Adult Education \\ (EJA).
}
Vanuberci Franco Monteiro da Silva ${ }^{1}$, Elaini Soares de Lima ${ }^{1}$, Arnaldo Gonçalves de Campos², Ronaldo Eustáquio Feitoza Senra²

${ }^{1}$ Graduado (a), Instituto Federal de Educação, Ciência e Tecnologia de Mato Grosso - Campus São Vicente - Núcleo Avançado de Jaciara, MT, Brasil.

${ }^{2}$ Professor, Instituto Federal de Educação, Ciência e Tecnologia de Mato Grosso - Campus São Vicente - Núcleo Avançado de Jaciara, MT, Brasil.

\begin{abstract}
Resumo
O presente trabalho teve como objetivo compreender as concepções dos educandos do $2^{\circ}$ segmento da Educação de Jovens e Adultos - EJA da Escola Estadual Marechal Rondon, acerca dos resíduos sólidos urbanos (RSU). A escola além de ser um centro de referência para esta modalidade educativa permite que o trabalho pedagógico se desenvolva por meio de diversas práticas e experiências diversificadas. A pesquisa descreve uma das experiências pedagógicas desenvolvidas neste contex to da EJA que ocorreu entre o período de novembro de 2013 a setembro de 2014 com 20 educandos, dos quais 08 educandos eram do sexo feminino e 12 do sexo masculino. A metodologia adotada no desenvolvimento da pesquisa foi o estudo de caso e utilizou-se de vários instrumentos para a coleta de dados tais como observação participante e questionários, além da realização de uma intervenção pedagógica que ocorreu em etapas tais como: apresentação da intervenção à turma; realização de diagnóstico conceitual sobre RSU; aulas teóricas sobre a temática; oficina sobre os 3 Rs (reduzir, reutilizar e reciclar) e; aula de campo (visita técnica) ao barracão de reciclagem do município. Os resultados obtidos na pesquisa demonstraram que o público pesquisado apresenta baixo nível de conhecimento sobre a temática em questão, que é de alta relevância no contexto da comunidade local, bem como na sociedade geral. Entretanto, percebe-se também, que ao trabalhar com uma problemática de alcance local, de maneira adequada, temas como Resíduos Sólidos Urbanos passam a ganhar maior importância no processo de construção de conhecimento desses educandos. Além disso, oportuniza-se ainda o protagonismo do indivíduo, abrindo espaço para a formação de cidadãos muito mais comprometidos com as causa sociais ao seu entorno.
\end{abstract}

Palavras-chaves: Ciências Naturais. Resíduos Sólidos Urbanos,. Educação de Jovens e Adultos - EJA.

\begin{abstract}
This study aimed to understand the conceptions of the students of the 2nd segment of the Youth and Adult Education - EJA of the State School Marechal Rondon, about municipal solid waste (MSW). The school in addition to being a center of excellence for this educational modality allows the pedagogical work develops through different practices and different experiences. The research describes a pedagogical experiences developed in this context of adult education that occurred between the period of November 2013 to September 2014 with 20 students, of which 08 learners were female and 12 male. The methodology used in the research was the case study and used a variety of instruments for data collection such as participant observation and questionnaires, as well as holding an educational intervention that took place in stages such as class to the intervention of presentation; realization of conceptual diagnosis of MSW; lectures on the subject; workshop on the 3 Rs (reduce, reuse and recycle) and; field class (technical visit) at the municipal recycling shed. The results of the survey showed that the public has researched low level of knowledge on the subject in question, which is of high relevance in the context of the local community and society in general. However, it is clear also, that when working with a local reach problematic properly, issues such as Municipal Solid Waste start to become more important in the construction of knowledge of these students. In addition, it provides an opportunity even the individual's role, making room for the formation of more citizens committed to the social cause to their surroundings.
\end{abstract}

Keywords: Natural Sciences, Solid Waste. Youth and Adult Education - EJA. 


\section{Introdução}

O presente trabalho aborda o tema: Resíduos Sólidos Urbanos (RSU) dentro do Ensino de Ciências na Educação de Jovens e Adultos (EJA), com a perspectiva de se compreender como a questão é abordada nesta modalidade educativa, sob o ponto de vista de se formar indivíduos aptos a exercerem a cidadania na promoção da saúde humana e do meio ambiente.

A pesquisa propõe discutir sobre a sensibilização dos educandos quanto à temática dos resíduos sólidos urbanos, já que com esta nomenclatura o "tão falado e discutido" lixo se modifica na nomenclatura para resíduos por conta da prerrogativa da lei atual (BRASIL, 2010). Então, esta temática com nova roupagem (de resíduos sólidos) aparece no desenvolvimento do Ensino de Ciências como um fenômeno que precisa ser compreendido nas suas dimensões socioambientais. Nesta perspectiva a Educação Ambiental pode ser uma das molas propulsoras de transformações das relações entre a sociedade e o meio.

De acordo com Gouveia (2012), o gerenciamento inadequado dos resíduos sólidos urbanos gera diretamente outros impactos importantes, tanto ambientais quanto na saúde da população. Através dessa abordagem, espera-se, portanto, conseguir enfatizar melhor sobre a importância da Educação Ambiental e do Ensino de Ciências na modalidade da EJA e a sensibilização para as questões dos resíduos sólidos.

De acordo com os Parâmetros Curriculares Nacionais (PCNs, 1998), o Ensino de Ciências deve ser proposto como um processo em que o educando possa compreender o movimento de resignificar o mundo, de estabelecer explicações, compreender os fenômenos sociais e ambientais, sendo o sujeito da sua aprendizagem pela mediação do educador e dos outros educandos, levando em conta os elementos culturais e o conhecimento científico. Um ensino que promova o educando e lhe dê "condições de continuamente colher e processar informações", avaliando e posicionando-se criticamente diante das situações. A problemática que motivou a realização e desenvolvimento dessa pesquisa consistiu no fato de se perceber que a questão ambiental e principalmente o tratamento e destinação dos resíduos sólidos urbanos (RSU) é uma temática frequente nos debates no Conselho Municipal de Meio Ambiente de Jaciara-MT.

A partir de Agosto de 2010 foi sancionado a Política Nacional de Resíduos Sólidos (PNRS), onde ficaram estipuladas as diretrizes para o planejamento e a gestão dos resíduos no país (BRASIL, 2010). Tal Lei trata ainda, sobre a obrigatoriedade da preparação de planos municipais de gerenciamento de resíduos, além do estabelecimento de prazos para a erradicação dos lixões e a implantação da coleta seletiva. Sendo assim, o Conselho Municipal de Meio Ambiente, em ação conjunta com a Secretaria Municipal de Meio Ambiente, vêm articulando ações no sentido de realizar na cidade de Jaciara a implantação da coleta seletiva, tratamento e reciclagem dos seus resíduos sólidos urbanos.

Apesar da obrigatoriedade da preparação de planos municipais de gerenciamento de resíduos manifestada na nova PNRS, Oliveira Neto et al., (2014), relatam que entre os 5.507 municípios brasileiros pesquisados, $63,6 \%$ usavam os "lixões" como forma de destino final à esses resíduos, sendo uma forma inadequada de armazená-los. Segundo o mesmo autor, o aterro sanitário, o modo mais indicado de depositar os resíduos, é utilizado por apenas 13,8\% dos municípios brasileiros.

Neste contexto, se há o ganho na prerrogativa legal é preciso um processo educativo permanente para que se efetive tais políticas públicas. Entende-se que a escola se manifesta como um ambiente altamente propício para as discussões sobre as questões vinculadas à qualidade de vida e bem estar dos indivíduos e do entorno das comunidades e municípios. Para Narcizo (2009), mais do que ensinar termos técnicos e definições, é dever da escola ensinar a amar o ambiente, a reconhecê-lo como um lar, respeitando-o e preservando-o. Para que essa possibilidade se torne realidade, o mesmo autor ressalta ainda que é necessário que os próprios professores entendam o ambiente como tal, sem distinções entre casa, rua ou escola.

Sendo assim, o presente trabalho teve como objetivo compreender como os conceitos referentes ao tema Resíduos Sólidos Urbanos (RSU) estão sendo percebidos pelos educandos de 
Ciências do $2^{\circ}$ segmento do Centro de Educação de Jovens e Adultos (CEJA), na Escola Marechal Rondon, no município de Jaciara - MT.

\section{Metodologia}

\subsection{Local de Desenvolvimento da pesquisa}

A presente pesquisa foi realizada durante o mês de agosto de 2013 a setembro de 2014, no Centro de Educação de Jovens e Adultos (CEJA) - Escola Estadual Marechal Rondon, localizado na cidade de Jaciara-MT.

Durante a realização da pesquisa, a escola contava com duas turmas da EJA do $2^{\underline{0}}$ segmento ( $6^{\circ}$ a $9^{\circ}$ ano), e aulas de Ciências no período matutino das $07: 00 \mathrm{~h}$ as $11: 00 \mathrm{~h}$ e noturno das $19 \mathrm{~h} 00$ às 22:30h. Todos os sujeitos da pesquisa eram oriundos do perímetro urbano da cidade.

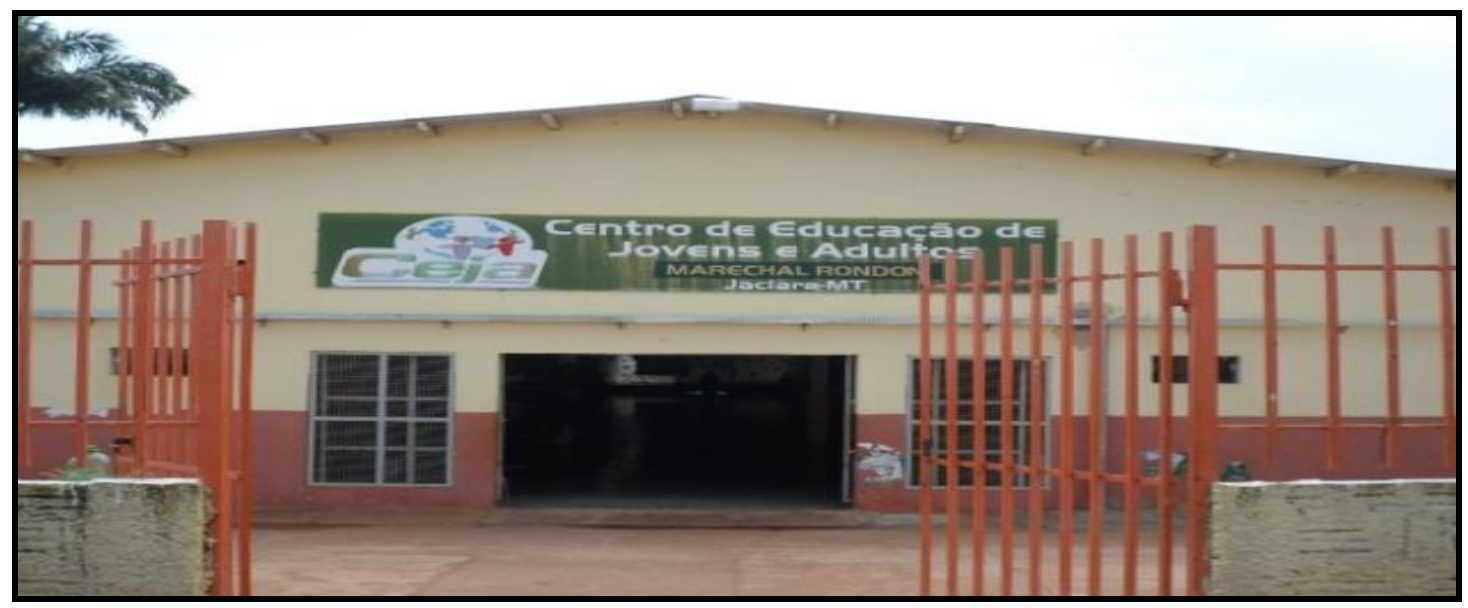

Figura 01 - Centro de Educação de Jovens e Adultos (CEJA) - Marechal Rondon (SILVA e LIMA, 2014)

\subsection{Sujeitos da pesquisa}

Os sujeitos envolvidos na pesquisa foram os educandos da Educação de Jovens e Adultos (EJA), do $2^{\mathrm{o}}$ segmento ( $6^{\circ}$ a $9^{\circ}$ ano), regularmente matriculados no período noturno da referida escola. Durante o desenvolvimento da pesquisa a turma contava com 20 educandos regularmente matriculados, dos quais 08 educandos do sexo feminino e 12 do sexo masculino.

\subsection{Metodologia de pesquisa}

A metodologia adotada na pesquisa foi o estudo de caso e privilegiou como coleta de dados o uso de questionários e a observação participante. Para Oliveira (2011), o questionário fornece subsídios reais do universo ou da amostra pesquisada, por isso, é considerado um importante instrumento de pesquisa. Em relação à observação, Marconi e Lakatos (2010), afirma que essa técnica consiste na participação real do pesquisador na comunidade ou grupo. Ainda segundo Gil (2010), esse procedimento de combinar diferentes técnicas para coleta de dados é importante para garantir a profundidade necessária ao estudo e a inserção do caso em seu contexto, bem como para conferir maior credibilidade aos resultados. 


\subsection{A coleta de Dados}

Quanto aos procedimentos de desenvolvimento, a pesquisa ocorreu em etapas organizadas da seguinte forma: Inicialmente foi apresentada a temática dos RSU à turma através de uma breve abordagem, o projeto de intervenção pedagógica a ser realizado; posteriormente procedeu-se a aplicação de um questionário com fins de diagnosticar o conhecimento dos educandos sobre a questão dos RSU antes e depois pesquisa; em seguida foi realizada uma aula teórica expositiva, esclarecendo conceitos e princípios sobre RSU; outra etapa da pesquisa ocorreu por meio de uma oficina que abordou sobre a questão dos 3RS (reduzir, reutilizar e reciclar). Para finalizar as atividades do projeto, realizou-se uma aula de campo (visita técnica) ao barracão de reciclagem do município.

\section{Resultados e discussão}

A compreensão dos resultados da pesquisa foi constituída por etapas distintas, alternadas conforme a seqüência dos procedimentos adotados nas atividades realizadas durante a pesquisa, sendo subdivididas da seguinte forma: a) Diagnóstico do conhecimento da turma sobre RSU; b) Aula teórica sobre RSU; c) Palestra sobre o legado da I Conferencia Municipal do Meio Ambiente; d) oficina sobre 3Rs (reduzir, reutilizar e reciclar), e) Visita técnica ao barracão de reciclagem do município.

\subsection{O Diagnóstico}

Quando questionados no início da pesquisa, sobre o tema resíduos sólidos urbanos (RSU), $65 \%$ dos educandos pesquisados firmaram desconhecer o assunto. Apenas $45 \%$ desses educandos afirmaram que já tinham conhecimento a respeito do assunto. Estes dados revelam que a temática do lixo, ao se tornar Resíduos Sólidos Urbanos é recente e deve ser trabalhada nas escolas. Quando o mesmo questionário foi aplicado no final da pesquisa, revelou resultados bastante satisfatórios, onde $95 \%$ dos educandos afirmaram conceitualmente demonstrando que houve construção do conhecimento pela mudança conceitual do lixo para resíduos. Dessa forma, justifica se a proposição apresentada por Narcizo (2009), onde o mesmo relata que a Educação Ambiental precisa ser entendida como uma importante aliada do currículo escolar na busca de um conhecimento integrado que supere a fragmentação do conhecimento, tendo em vista a emancipação dos sujeitos.

Ao serem interrogados sobre destino correto dos resíduos sólidos urbanos (RSU), gerados em sua casa, na escola e/ou na cidade, $65 \%$ dos educandos responderam não saber qual a destinação adequada, dessa forma apenas $35 \%$ dos educandos pesquisados sabiam o destino correto desse material. Quando questionados pela segunda vez, após o término da pesquisa, $90 \%$ reponderam corretamente, sobre a destinação adequada aos RSU, ficando, portanto, apenas $10 \%$ entre as respostas erradas. Sendo assim, os resultados obtidos na pesquisa, demonstraram que o público pesquisado apresenta baixo nível de conhecimento sobre a temática em questão, que é de alta relevância no contexto da comunidade local, bem como na sociedade em geral. Entretanto, percebe-se também, que ao se trabalhar com uma problemática de alcance local, de maneira adequada, temas como Resíduos Sólidos Urbanos ganharão maior importância no processo de construção de conhecimento desses educandos.

Quando questionados sobre o descarte incorreto dos resíduos sólidos urbanos causa algum efeito prejudicial ao meio ambiente, $90 \%$ dos educandos responderam positivamente que causam algum tipo de impacto ambiental, apenas $10 \%$ dos educandos afirmaram não causar nenhum tipo de impacto ambiental. As respostas dadas pelos educandos ao referido questionamento, demonstram que, embora de forma bastante simples, já existem fortes indícios de consciência ambiental entre os educandos pesquisados e os impactos causados por estes resíduos. Depois da pesquisa foi aplicado novamente o mesmo questionário, onde $100 \%$ dos educandos afirmaram que o descarte dos resíduos sólidos em lugares incorreto causa transtornos ao meio ambiente.

Ao buscar compreender as relações entre a produção de RSU e a coleta seletiva, os educandos foram questionados sobre as cores e símbolos de lixeiras para o processo da coleta destes resíduos, os 
resultados demonstraram que esses educandos já tiveram algum tipo de informação sobre esses coletores seletivos. Entretanto, o nível de informações desses educandos sobre todo o processo da coleta ainda é bastante baixo. Segundo depoimento de alguns educandos, antes da pesquisa, os mesmos não davam importância em memorizar as cores dos coletores aos seus respectivos resíduos, pois de acordo com os mesmos, se trata de algo que eles não têm contato rotineiramente. Aqui cabe uma reflexão que o processo educativo deve ser permanente e que apenas "colocar lixeiras coloridas" no pátio da escola por si só, não muda os hábitos.

Dessa forma, entendemos que há uma grande lacuna nas relações entre a produção de RSU, fruto do consumo humano e o processo de uma Educação Ambiental que se quer refletir principalmente sobre este consumo e as relações socioambientais. Assim, é importante o trabalho da Educação Ambiental a partir de uma problemática contextualizada para agir no local e se pensar no global.. Dessa forma, percebe-se que há um maior interesse dos educandos em se envolver nas causas socioambientais, gerando com isso, um aprendizado significativo e contextualizado durante o processo de ensino-aprendizado.

Além disso, oportuniza-se ainda o protagonismo do indivíduo, abrindo espaço para a formação de cidadãos muito mais comprometidos com as causa sociais ao seu entorno. Sobre esse aspecto, Freire (2002), faz a seguinte sugestão: "meu papel fundamental, ao falar com clareza sobre o objeto, é incitar o aluno a fim de que ele, com os materiais que ofereço, produza a compreensão do objeto em lugar de recebê-la na íntegra de mim".
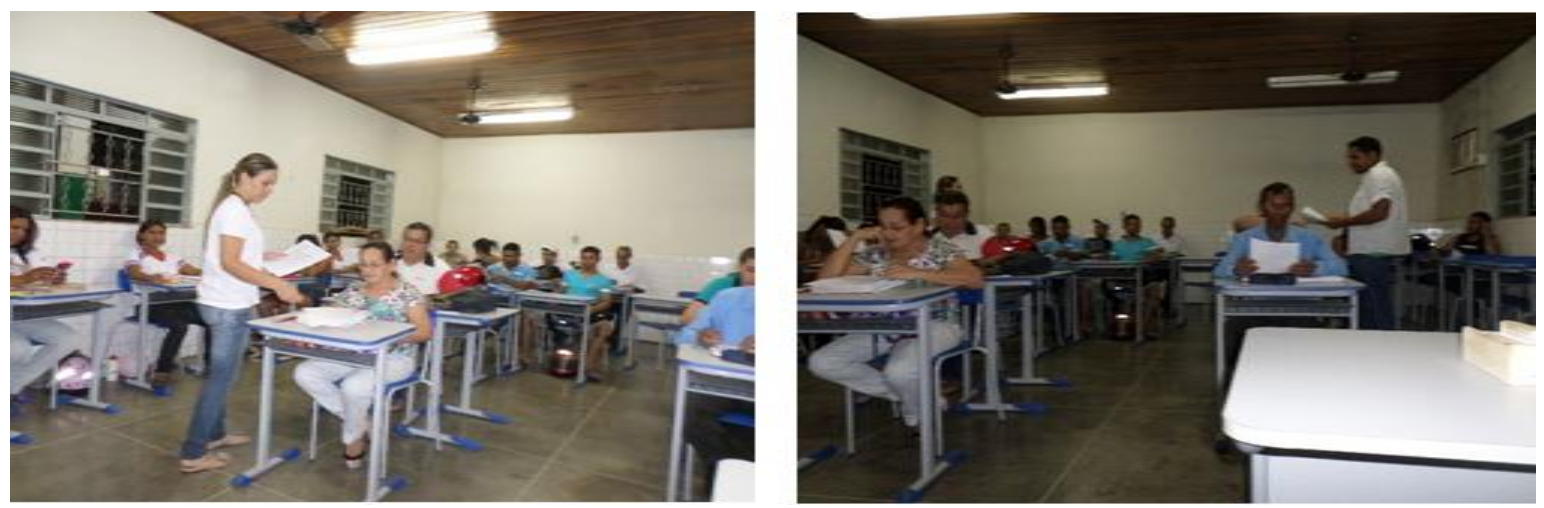

Figura 2a e 2b - Momento da aplicação e reaplicação o do questionário (SILVA e LIMA, 2014)

\subsection{Aula Teórica Sobre RSU}

A aula teórica expositiva teve como propósito esclarecer sobre os principais impactos associados ao inadequado gerenciamento dos Resíduos Sólidos Urbanos (RSU), abordando a questão da gestão estratégica acerca dos mesmos. (FIGURA 3a e 3b).

Após a aula foi possível verificar que os educandos já conseguiam distinguir com certa clareza os diversos assuntos relacionados ao tema resíduos sólidos. Sendo assim, a aula teórica constituiu-se em um espaço não só para o aprendizado, mas também um ambiente aberto, no qual os educandos puderam debater, questionar e propor novas discussões relacionadas com a problemática no contexto local.

O debate sobre a questão dos resíduos sólidos urbanos em sala de aula permitiu a constatação de que, apesar da maioria dos indivíduos integrantes da pesquisa não terem conhecimentos bem formulados sobre o assunto (pelo fato de haver uma mudança na nomenclatura), já existia uma preocupação sobre a relação dos resíduos sólidos com a qualidade da saúde humana e ambiental. Dessa forma, entende-se que há a necessidade de que todo cidadão tenha conhecimento sobre as políticas públicas no seu entorno. Sobre esse aspecto, Gouveia (2012) ressalta que as decisões que envolvem o gerenciamento de resíduos sólidos urbanos são fundamentalmente decisões sobre saúde pública e requerem, portanto, a integração entre políticas econômicas, sociais e ambientais. De acordo 
com Souza e Cordeiro (2009), analisando o nível mais operacional e técnico, o tratamento dado no Brasil para seus resíduos sólidos ainda está muito aquém de uma situação adequada. O mesmo autor ressalta ainda, que a grande maioria dos materiais é disposta inadequadamente, e as experiências de coleta seletiva ainda são muito pontuais.

Sobre a importância da participação na construção da sustentabilidade Lozano (2012), afirma que os processos democráticos aos quais as políticas públicas tiveram grande influência após a constituinte de 1988, requer uma compreensão que estes processos de gestão descentralizada são recentes na dimensão histórica da sociedade brasileira como um todo.

Dessa forma, entende-se que as discussões sobre a questão dos resíduos soídos urbanos (RSU), ainda são bastante insipientes em quase todo o Brasil, carecendo, portanto, de muitas discussões para que se possa reivindicar e propor políticas públicas que venham atender as reais demandas sociais de acordo as necessidades específicas de cada localidade. Para o mesmo autor, os resíduos como também o saneamento básico não têm sido prioridade nos planos de governo, visto que são obras caras e de longo prazo para observação de seus resultados.
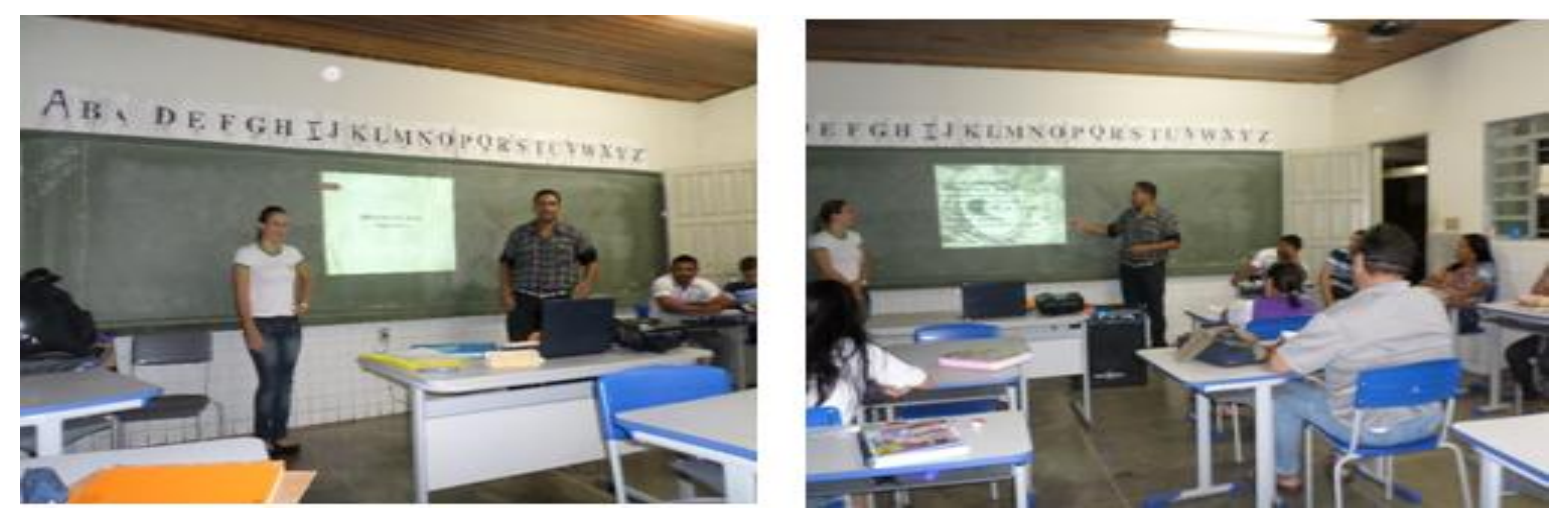

Figura 3a e 3b - Aula teórica sobre Resíduos Sólidos Urbanos (SILVA e LIMA, 2014).

\subsection{A Palestra}

A palestra teve como interesse fundamental discutir sobre a temática ambiental, tratada na I Conferência Municipal do Meio Ambiente, tendo como objetivo principal apresentar o legado deixado por esta conferência no município de Jacira. A referida palestra contou com o apoio técnico da SAMA (Secretaria adjunta do Meio Ambiente. Conforme (FIGURA 04).

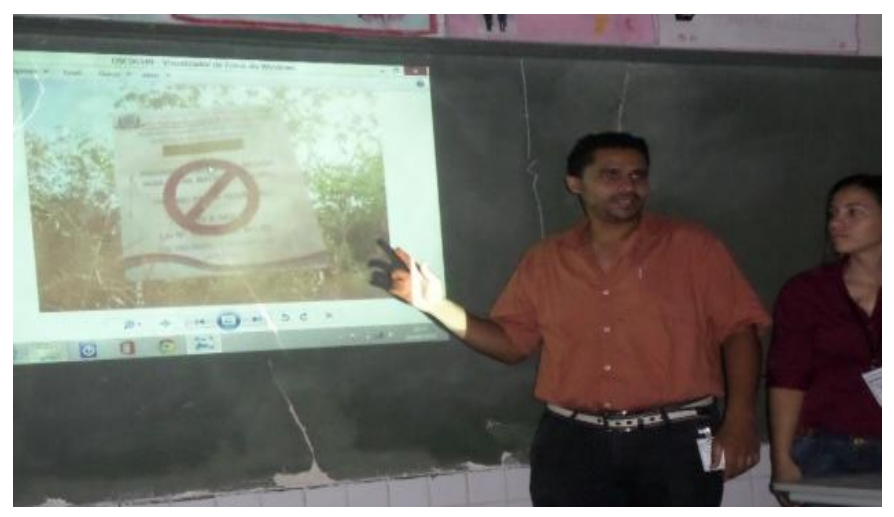

Figura 04 - Palestra realizada na turma $2^{\circ}$ segmento CEJA Marechal Rondon.

(SILVA e LIMA, 2014). 
Os educandos conseguiram vislumbrar de forma mais evidente como se efetiva as políticas públicas após a palestra sobre o legado da Conferência de Meio Ambiente do Município de Jaciara. Buscou-se durante a palestra a interação com esses educandos por meio do diálogo para a contextualização dos conteúdos discorridos, interligando-os ao seu cotidiano. Neste sentido, Narcizo (2009), enfatiza que a Educação Ambiental deve ser trabalhada na escola não por ser uma exigência do Ministério da Educação, mas segundo o autor, é a única forma de aprendermos e ensinarmos que nós, seres humanos, não somos os únicos habitantes deste planeta e que o respeito a todas as outras formas de vida são fundamentais.

Nesta etapa os educandos demonstraram bastante interesse, tanto nas questões tratadas, bem como nas explicações apresentadas, permanecendo atentos durante toda a apresentação da palestra. A interação buscada inicialmente foi respondida através de vários questionamentos que serviram para sanar todas as dúvidas, as quais, os mesmos tinham sobre um assunto, que até então, segundo a maioria dos educandos se quer haviam ouvido falar.

Um aspecto que despertou bastante interesse dos educandos durante a palestra foi o fato de saber que o Programa Nacional de Resíduos Sólidos (PNRS), estabelecido pela Lei 12.305 de 02/08/2010, estipula o prazo máximo do ano de 2014 para que todos os municípios implantem seus próprios Planos Integrados de Gestão de Resíduos Sólidos Urbanos (OLIVEIRA NETO et al., 2014). Dessa forma, a maioria dos educando compreenderam que essa questão é de grande relevância para a comunidade local.

\subsection{A Oficina}

Na oficina foi abordado sobre o princípio dos 3Rs (reduzir, reutilizar e reciclar). Inicialmente procedeu-se uma divisão da turma em dois grupos, visando possibilitar que todos protagonizassem o processo de construção do conhecimento, além de permitir uma melhora na dinâmica de realização dos trabalhos.

No primeiro momento os grupos discutiram sobre a possibilidade de se reduzir o consumo de papel, sobretudo nas instituições públicas de ensino, pois segundo as discussões abordadas pelos educandos, além dos ganhos financeiros, têm-se a oportunidade de estar aplicando de forma prática, os princípios de educação ambiental numa pareceria entre a escola e os seus estudantes.

Posteriormente os grupos se organizaram para demonstrar de forma prática, alternativas sustentáveis para a reutilização de produtos que normalmente são descartados na natureza, sendo que poderiam estar sendo reutilizados de forma racional. O primeiro grupo realizou a confecção de caixinhas de presentes a partir de caixas de leite. O segundo utilizou garrafas pets para a confecção de mudas de plantas diversas. (FIGURA 5a e 5b). Para Gouveia (2012), a reutilização de resíduos sólidos gera benefícios diretos, tanto na redução da poluição ambiental causada pelos aterros e depósitos de lixo como em benefícios indiretos relacionados à conservação de energia.
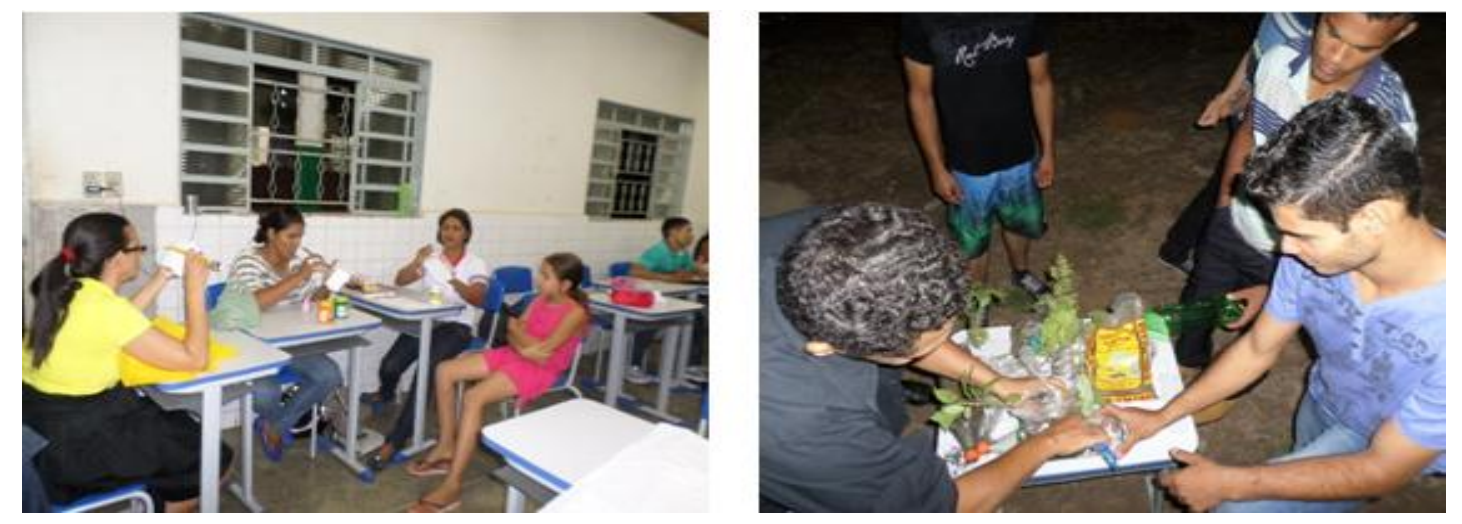

Figura $5 a$ e $5 b$ - Oficina realizada com a turma $2^{\circ}$ segmento CEJA Marechal Rondon (SILVA e LIMA, 2014) 
Foi abordado também a possibilidade de se proceder a reciclagem dos produtos que não possuem qualidades úteis para o reaproveitamento. Foi enfatizado ainda, que a reciclagem seria a última alternativa sustentável a ser adotada no princípio dos 3 Rs, pois antes de reciclar há uma necessidade de conscientização para a redução do uso indiscriminado e da reutilização de materiais que apresentam esse potencial.

Essas práticas inicialmente foram desenvolvidas com o intuito de fazer com que os educandos pudessem aprender a produzir mudas, para o estabelecimento de uma horta vertical além de um material que lhes trouxesse algum retorno. Diante do presente contexto, verificou-se o sucesso da atividade, pois, todos os educandos quiserem levar para suas casas os resultados desta oficina.

Sobre a situação experimentada nessa etapa da pesquisa, Freire (2002), faz a seguinte constatação:

\begin{abstract}
Não há ensino sem pesquisa e pesquisa sem ensino. Esses que-fazeres se encontram um no corpo do outro. Enquanto ensino continuo buscando, reprocurando. Ensino porque busco, porque indaguei, porque indago e me indago. Pesquiso para constatar, constatando, intervenho, intervindo educo e me educo. Pesquiso para conhecer o que ainda não conheço e comunicar ou anunciar a novidade (FREIRE, 2002).
\end{abstract}

Dessa forma, percebeu-se que os educandos conseguiram idealizar e testar de forma prática, aspectos relacionados à consciência ambiental, trazendo assim, o interesse deles em serem agentes multiplicadores dessas idéias.

\title{
3.5 A Visita Técnica
}

Para finalizar as atividades da presente intervenção pedagógica, realizou-se uma aula de campo (visita técnica), ao barracão que recebe todo o material com potencial de ser reciclado. Este barracão já vem sendo utilizado por algum tempo para receber todo o resíduo sólido urbano (RSU) do Município de Jaciara-MT. (FIGURA 6a e 6b).

Segundo abordagem apresentada por Andrade e Massabni (2011), as atividades práticas no Ensino de Ciências podem se configurar, através do estudo do meio, da experimentação, de visitas com observações, entre outras.
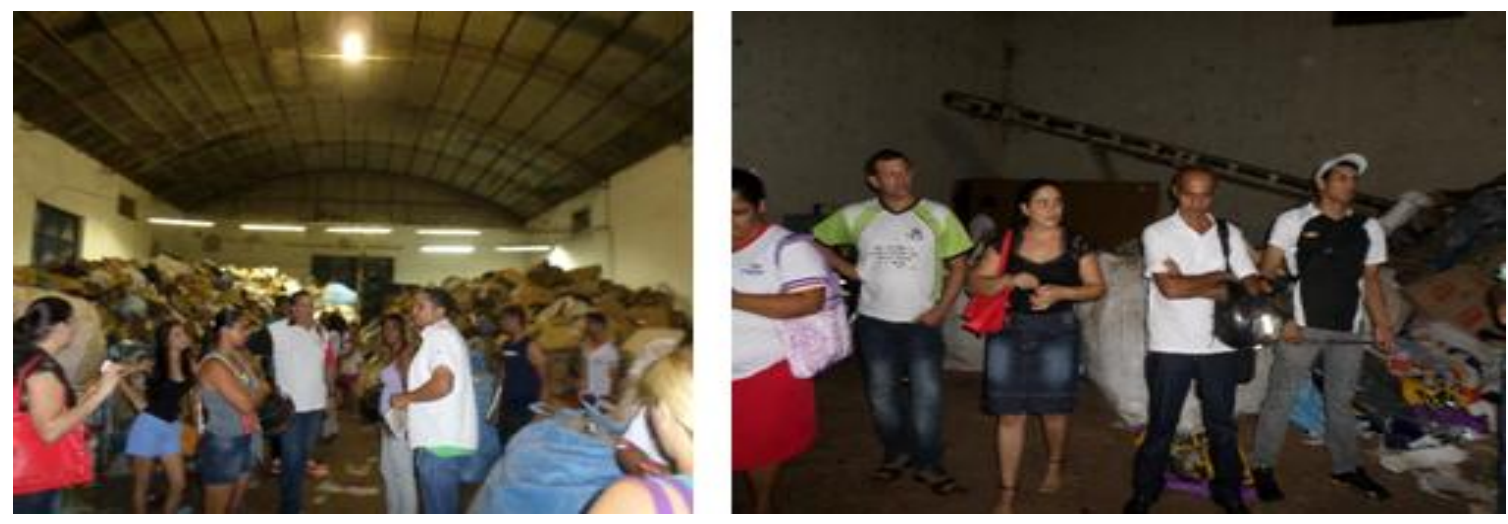

Figura 6a e 6b - Visita técnica ao barracão de separação e reciclagem (SILVA e LIMA, 2014)

Neste momento os educandos conseguiram distinguir "in loco" a maneira errada e maneira correta de descarte dos RSU. Essa foi uma oportunidade de se colocar em prática o conhecimento adquirido por eles nas experiências com as etapas anteriores.

Quando se depararam com a grande quantidade de resíduos acumulados aleatoriamente no barracão, muitos educandos se assustaram ao constatar na prática que muitas coisas não estavam sendo organizadas conforme haviam estudado e discutido em outras etapas anterior, como por exemplo a coleta seletiva por meio dos latões coloridos, já que na seleção dos resíduos sólidos em um barracão de reciclagem muitas vezes a classificação destes resíduos ocorre de outra maneira. 
Entretanto, houve algumas manifestações de satisfação por parte de alguns educandos, ao perceber que o município já vem desenvolvendo alguma atividade voltada para a questão ambiental, como é a parceria com a Secretaria de Meio Ambiente e a Associação de Catadores de Materiais Reciclados do município.

\section{Considerações finais}

A pesquisa desenvolvida serviu para tornar visível que os educandos pesquisados têm consciência de que é importante se trabalhar com o tema resíduo sólido urbano (RSU), no Ensino de Ciências. Um dos fatores que supostamente levam ao interesse a sociedade pela temática é o fato de que os problemas relacionados às questões ambientais estarem cada vez mais em destaque através dos acontecimentos veiculados pela mídia em geral e também presentes no nosso dia-a-dia.

No entanto, percebeu-se que o trabalho pedagógico sobre Educação Ambiental precisa ser intensificado, e desenvolvido com maior comprometimento. Apesar de a escola ser munida de materiais, contudo existe certa resistência, por parte de alguns professores em trabalhar o assunto na rotina da escola.

Dessa forma, entende-se que é dever da escola promover a formação de indivíduos que sejam comprometidos com a melhoria da qualidade de vida da sociedade, com a conservação e preservação da biodiversidade e sustentabilidade do planeta.

O desenvolvimento dessa pesquisa foi compensador, uma vez que abriu novos horizontes, além de outras perspectivas sobre a Educação, tanto com as leituras para a fundamentação das aulas quanto com a prática da intervenção em sala de aula. A oportunidade de conhecer e inserir-se neste contexto escolar trouxe outra possibilidade de atuação docente, não se limitando apenas a uma pesquisa ou ainda uma intervenção pedagógica, na área de Ciências.

\section{Agradecimentos}

À Coordenação de Aperfeiçoamento de Pessoal de Nível Superior (CAPES) pelo subsídio através do Programa de Consolidação das Licenciaturas (PRODOCENCIA) Edital 019/2013, processo № 113.657, e do Programa Institucional de Bolsa de Iniciação à Docência (PIBID) Edital № 061/2013, processo № 128.570, IFMT/Campus São Vicente/Sub Projeto Ciências.

\section{Referencias}

ADEODATO, Marise Tissyana Parente Carneiro. Análise das estratégias do projeto para incorporação de princípios e indicadores da sustentabilidade em políticas públicas no município de Jaboticabal SP. 2005. 264 f. Dissertação (Mestrado em Engenharia Urbana) - Universidade Federal de São Carlos, São Carlos, 2005.

ANDRADE, M.L.F e MASSABNI, V.G. O desenvolvimento de atividades práticas na escola: um desafio para os professores de ciências. Revista Ciência \& Educação, v. 17, n. 4, p. 835-854, 2011.

BRASIL. Secretaria de Educação Fundamental. Parâmetros curriculares nacionais: Ciências Naturais/Secretaria de Educação Fundamental. Brasília: MEC/SEF, 1998. 138p.

BRASIL. Parâmetros curriculares nacionais: Ciências Naturais/Secretaria de Educação Fundamental. Brasília: MEC/SEF, 1998. 138p.

BRASIL. Lei no 12.305 de 02 de Agosto de 2010. Institui a Política Nacional de Resíduos Sólidos; altera a Lei n 9.605, de 12 de fevereiro de 1998; e dá outras providências. Diário Oficial da União 2010; 3 ago. 
[acessado 20/10 de 2014 ]. Disponível em: http://www.mncr.org.br/box_2/instrumentos-juridicos/leise-decretos-federais/Lei\%20\%2012.305-2010\%20Politica\%20de\%20Residuos\%20Solidos.pdf/view.

FREIRE, Paulo. Pedagogia da autonomia: saberes necessários à prática educativa. São Paulo: Paz e Terra, 2002.

FREIRE, Paulo. Naõ há Docência sem Discência - acessado 05/01/15

Disponível em: https://sites.google.com/site/pibidifpi/.../nao-ha-docencia-sem-discencia

GIL, Antônio Carlos. Como elaborar projetos de pesquisa. 4. Ed. São Paulo: Atlas, 2002.

GOUVEIA, Nelson. Resíduos sólidos urbanos: impactos socioambientais e perspectiva de manejo sustentável com inclusão social. Ciência \& Saúde Coletiva, 17(6):1503-1510, 2012.

LOZANO, Marisa Cubas. Um olhar para a gestão de resíduos sólidos urbanos a partir de indicadores de sustentabilidade. (Dissertação de Mestrado) Programa de Pós-Graduação em Engenharia Ambiental/ Universidade Federal de São Carlos, 2012.

MARCONI, M. A.; LAKATOS, E. M. Fundamentos de metodologia científica. 7 ed. São Paulo: Atlas, 2010.

NARCIZO, Kaliane Roberta dos Santos. Uma análise sobre a importância de trabalhar Educação Ambiental nas escolas. Rev. eletrônica Mestrado em Educação Ambiental. ISSN 1517-1256, v. 22, janeiro a julho de 2009.

OLIVEIRA, M. M. de. Como Fazer projetos, monografias, dissertações e teses. 5 ed. Rio de Janeiro: Elsevier, 2011.

OLIVEIRA NETO, Raul; SOUZA, Luis Eduardo de; PETTER, Carlos Otávio. Avaliação da gestão integrada de resíduos sólidos urbanos no Brasil em comparação com países desenvolvidos. Revista Monografias Ambientais - REMOA v.13, n.5, dez. 2014, p.3809-3820.

SOUZA, Ricardo Gabbay; CORDEIRO, João Sérgio. Gestão estratégica de resíduos sólidos: utilização do balanced scorecard. planejamento e políticas públicas | ppp | n. 32 | jan./jun. 2009. 